\title{
Green computing - The New Era of Energy Efficient Computing
}

\author{
Rupali Dhir \\ Assistant Professor \\ PCTE Group of Institutes \\ Baddowal, Ludhiana, \\ Punjab,India
}

\begin{abstract}
Green computing is the study and practice of using computing resources efficiently. It aims to reduce the use of hazardous materials, maximize energy efficiency during the product's lifetime, and promote recyclability or biodegradability of defunct products and factory waste. The plan towards green IT should include new electronic products and services with optimum efficiency.

Green computing strategies can help us to build a safe place for us to live in .If each one of us becomes successful in constructing a healthy environmental balcony for ourselves then trust us we can together make our mother earth a healthy and a happy place for us to survive here.
\end{abstract}

\section{Keywords}

Green Computing, E-waste, Save Mother Earth, Recycling, Eco-Friendly

\section{INTRODUCTION}

Thinking green means being aware of our interconnectedness with the world and reflecting on the unintended damage we cause nature in the daily course of our lives. Thinking green leads to acting green - taking corrective action to make environmental responsibility a reality. Green computing is the environmentally responsible use of computers and related resources

The goals are to reduce the use of hazardous materials, maximize energy efficiency during the product's lifetime, and promote recyclability or biodegradability of defunct products and factory waste. IT department is usually always the one department that uses the most amount of power which in turn is an excessive amount of overhead for a business as well as a source for toxic waste. Making IT "Green" can not only save money but help save our world by making it a better place through reducing and/or eliminating wasteful practices and using nontoxic materials with computing technology firmly woven into the fabric of daily life, computer science educators are ideally suited to contribute to Green Computing education and research. The introduction of green technology projects such as the Low Carbon ICT Project at the University of Oxford are indicative of a positive trend, although there is significant opportunity for theoretical and experimental research to be performed by computer scientists.

Computer science educators can lead the way by incorporating Green Computing ideas into the curriculum and by making these ideas and techniques accessible to educators in other disciplines. This paper describes current Green Computing principles and approaches for reducing energy use and, ultimately, the carbon footprint. Practical methods are introduced, with analysis of an empirical evaluation to support their use in the department and classroom and to offer insight into paths for Green Computing research. Although this paper focuses on technical approaches, the authors acknowledge that there are many other aspects of Green computing that deserve serious consideration.

\section{PROBLEMS}

Performance-wise, computer design has progressed staggeringly well and astonishingly fast but looking at it from a green perspective, the work is at its epoch. It takes a lot of energy to create, package, store, and move. Conventionally, manufacturing computers includes the use of lead, cadmium, mercury, and other toxics in general. Usually, computers can contain 4 to 8 pounds of lead alone, according to green experts.

It's no wonder that computers and other electronics make up two-fifths of all lead in landfills. To counter this growing pollution threat all over the world due to the growing use of electronic device in general and computers in particular there is a need to look for a eco-friendly computer. "Data center servers use 50 times the energy per square foot as an office [does]," says Mark Bramfitt, principal program manager at PG\&E. Data centers are the main reason behind energy consumption, Energy consumed by data centers in the United States and worldwide doubled from 2000 to 2005, according to Jonathan Koomey, a consulting professor at Stanford University and staff scientist at Lawrence Berkeley National Lab.

As a result, some companies are chasing cheaper data center power. Google is building a data center on Oregon's Columbia River to tap hydroelectric power, while Microsoft builds nearby in Washington for the same reason. Financial services company HSBC is building a data center near Niagara Falls. To keep servers at the right temperature, companies mainly rely on air-conditioning equipments. The more powerful the machine, the more cool air needed to keep it from overheating. By 2005, the energy required to power and cool servers accounted for about $1.2 \%$ of total U.S. electricity consumption, according to a report released in February by staff scientist Jonathan Koomey of Lawrence Berkeley National Laboratory and sponsored by chip manufacturer AMD (AMD). According to Gartner by 2010, about half of the Forbes Global 2000 companies will spend more on energy than on hardware such as servers. Energy costs, now about $10 \%$ of the average IT budget, could rise to $50 \%$ in a matter of years, Kumar says. Faster processors use more power, because they use too much power and their waste heat increases temperature for which air conditioning necessary, especially in server farms--between the computers and the HVAC. The waste heat also causes reliability problems, as CPU's crash much more often at higher temperatures.

\section{HISTORY}

One of the first manifestations of the green computing movement was the launch of the Energy Star program way 
back in 1992. Energy Star served as a kind of voluntary label awarded to computing products that succeeded in minimizing use of energy while maximizing efficiency. Energy Star applied to products like computer monitors, television sets and temperature control devices like refrigerators, air conditioners, and similar items. One of the first results of green computing was the Sleep mode function of computer monitors which places a consumer's electronic equipment on standby mode when a pre-set period of time passes when user activity is not detected. As the concept developed, green computing began to encompass thin client solutions, energy cost accounting, virtualization practices, eWaste, etc.

\section{WHY GREEN COMPUTING}

Green Computing is a discipline that studies, develops and promotes techniques for improving energy efficiency and reducing waste in the full life cycle of computing equipment from initial manufacture, through delivery, use, maintenance, recycling and disposal in an economically realistic way. While it is daunting to consider the ways in which the widespread use of computers is contributing to waste, it is encouraging to recognize that computer science researchers and educators can pursue solutions to reduce this wastefulness.

It is observed that most of the computer energy is often wasteful. This is because we leave the Computer ON even when it is not in use. The CPU and fan consume power; screen savers consume power even when the system is not in use. Insufficient power and cooling capacities can also results in loss of energy. It is observed that most of the data centers don't have sufficient cooling capacities. This result in environment pollution. This could be because of defects in Manufacturing techniques, packaging, disposal of computers and components. Another effect is because of toxicity. Computing power consumption of companies has reached a critical point. For example, an Ecommerce business with 100,000 servers can easily spend up to $\$ 20$ million a year on server power. Add another $\$ 10$ million for a/c cooling and it tops $\$ 30$ million a year in power alone. Clearly there is a huge potential for savings in their infrastructure. Despite the huge surge in computing power demands, there are many existing technologies and methods by which significant savings can be made. This series is dedicated to the ways a typical organization can reduce their energy footprint while maintaining required levels of computing performance. So why should a company promote green, or energy efficient computing? "Information Technology energy demand is growing 12 times faster than the overall demand for energy" and "Data centre's emits over 150 metric tons of $\mathrm{CO} 2$ per year, and the volume is increasing rapidly. (As a point of reference, a car produces 18 pounds of $\mathrm{CO} 2$ for every gallon of gasoline it uses.)" It is the need of the hour to educate people about the "GREEN" use of ICT. In order to promote these ideas and create standards and regulations various organizations have been formed. Many technology companies actually belong several of these to further their goals of becoming more "green".

\section{Role of computer merchant}

Computer merchant are applying green standards to their own operations. The advantages are:

Fear of a customer backlash

Desire to act like good corporate citizens

Earning opportunities
Sun created a Sun Eco office to oversee all of the company's green programs, including telecommuting but also core products such as low-power servers. Dell in February launched "Plant A Tree For Me," where consumers pay an extra \$2 for a laptop or \$6 for a desktop to plant trees aimed at offsetting the equivalent computer emissions. It launched www.dell.com/earth to tout its green policies.

\section{How to save energy}

1. Switch off your computer when you sleep you'll reduce your energy use by $810 \mathrm{kWh}$ per year and net a 67 percent annual savings.

2. Purchase LCD monitors - they use less energy and are not as hard on your eyes as CRTs.

3. Unplug the electronics if not in use.

4. Consider a smaller monitor - a 14-inch display uses 40 percent less energy than a 17 -inch one.

5. Enable the standby/sleep mode and power management settings on your computer Sleep mode or stand by: conserves energy by cutting off power to your display, hard drive, and peripherals. After a pre-set period of inactivity, your computer switches to a low power state. When you move your mouse or press any computer key, you exit sleep mode and your computer takes you back to its previous operating state. Sleep mode is an especially effective way to conserve battery power in a laptop computer.

6. Power off your monitor when you are not using it instead of using screen savers.

7. According the Department of Energy, "Vampire energy loss" represents between 5 and 8 percent of a single family home's total electricity use per year. On average, that equals one month's electricity. An easy solution to it is: a surge protector with a master control outlet. Simply plug your computer into the master outlet and your peripherals into the controlled outlets. The master outlet senses your computer powers down or goes into sleep mode and automatically shuts down the controlled outlets.

8. Your peripherals no longer suck up energy when they are in standby mode.

9. Buy vegetable or non-petroleum-based inks - they are made from renewable resources require hazardous solvent.

10. Save Paper when Printing: When it comes to the environment, one of the first places most offices can improve is the giant pile of discarded paper by the network printer. Aside from obvious things you can do on your own-like printing duplex, printing to PDF, previewing before printing, and not printing hundreds of copies of an email forward to plaster around the office - there are a few other tools you can use to minimize wasting paper and ink when printing

11. Recycling - Electronics Waste Can be Recycled. Recycling can be defined as the process of used materials processing into new useful materials with the aim to reduce environmental pollution. The recycling process is more environmentally friendly than the process of making new stuff because it can

Reduce the use of new raw materials, land degradation, pollution, and energy usage and also can reduce greenhouse gases.

\section{CONCLUSIONS \& FUTURE WORK}


The good news is that through modern technology, such as the Aqua forest suite of products, we can adopt greener IT processes which not only have an efficient and economic benefit to an organization, but will also fulfill the brief for the corporate and social responsibilities we all share Many governments worldwide have initiated energy-management programs, such as Energy Star, an international standard for energy-efficient electronic equipment that was created by the United States Environmental Protection Agency and has now been adopted by several other countries. Now we have future of Green computing. There is lot of technique with green computing .By using these technique we can save energy, pollution and any type of wastage in IT and environment.

In the future, we plan to conduct a more comprehensive series of case studies in classrooms to improve the understanding of how these techniques perform in real world scenarios. Information on repeatable power use benchmarking, including an automated web browsing benchmark, are available online (actlab.csc.villanova.edu). Additional guideline development is planned, with the goal of engaging more faculty, staff and students in Green Computing research, application and education.

\section{REFERENCES}

1. Green Computing The concept of Green Computing Aquaforest Limitrd www.aquaforest.com
2. (2006-10-23). "EPA Announces New Computer Efficiency Requirements". A report regulated by Jones, Ernesta.

3. www.en.wikipedia.org/wiki/Green_computing, accessed during May- July 2008

4. www.csi-india.org/green-computing, accessed during May- July 2008

5. www.technopreneur.net/informationdesk/sciencetechmagazine/2007/nov07/GreenComputing. pdf, accessed during May- July 2008

6. www.wipro.co.in/products/greenpc/html/0007clip.htm, accessed during May- July 2008

7. www.tech-faq.com/green-computing.shtml, accessed during May- July 2008

8. Srivastava, M (2007) Chemistry for Green Environment

9. Gary B. S (2002)Discovering Computers: Concepts for a Digital World, Complete Shelly Cashman Series:Complete

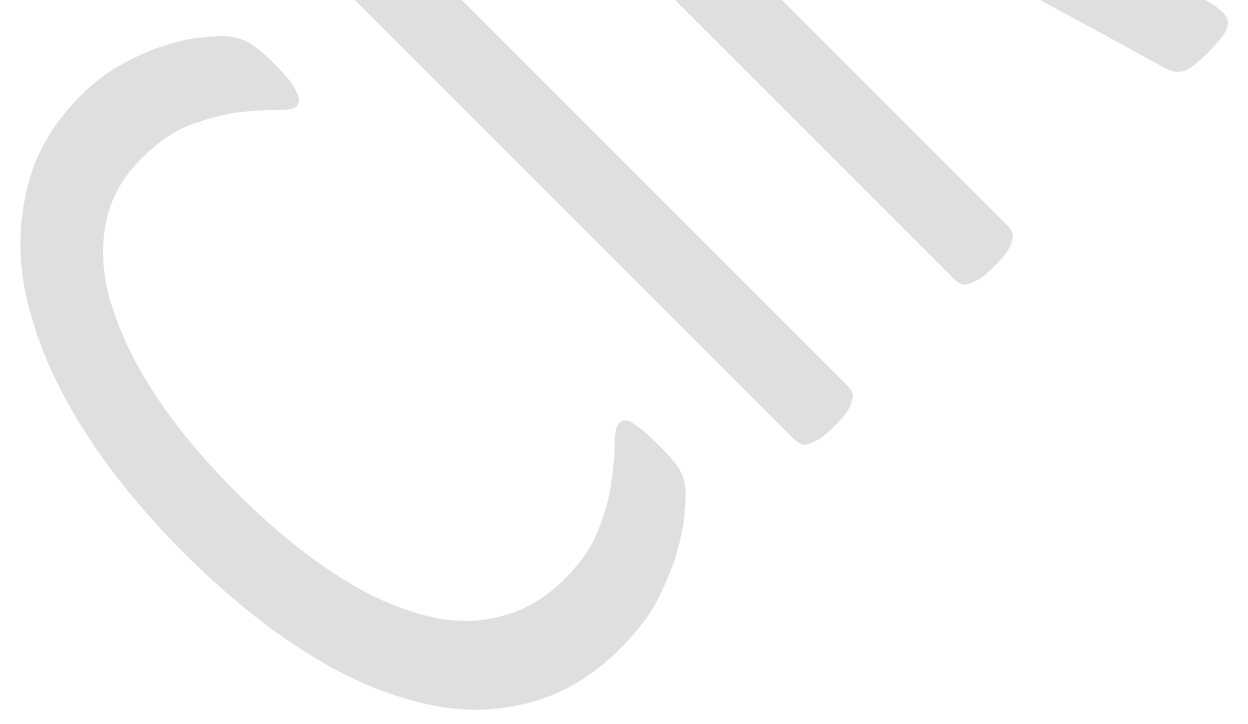

